\title{
Geoecology of small hydroelectric power stations on the rivers of the Moscow region, Russia
}

\author{
Veronika Luchkina ${ }^{1, *}$, Nikita Pronin $^{1}$ and Sergei Kondratiev ${ }^{1}$ \\ ${ }^{1}$ Moscow State University of Civil Engineering, 129337, 26, Yaroslavskoye Shosse, Moscow, Russia
}

\begin{abstract}
The aim of this paper is validation of possibility of using hydropower potential of local drops in water supply and water disposal systems of large enterprises and thermal power stations, reservoirs and other structures located on the territory of Moscow and Moscow Oblast; also there validated the possibility and feasibility of their hydropower potential use and consideration of geo-ecological factors such as geological setting and composition of soils on the territories of weirs, presence of forest vegetation, sorption characteristics and composition of soils significantly affecting the degree of protection of live streams against pollution. Therefore, they should be taken into consideration at conducting comprehensive assessment of the springs condition. Units of small HPPs may be installed at spillage of clarified water from sedimentation basins of thermal power stations, water purification facilities. Construction of small HPPs of such types should be realized within the frame of energy efficiency policy. Apart from incorporation of energy efficiency technologies they may contribute in power supply of enterprises at which they are constructed. Such stations may serve as a power supply reserve of certain consumers.
\end{abstract}

\section{Introduction}

Moscow Region (Moscow and Moscow Oblast, Russia) are located in the zone of effect of Moscow energy system ("Mosenergo"). As a structural unit of energy management Mosenergo is the largest of the regional systems funding the United Energy System of the Center. The profitability index of Moscow energy system is sufficiently high and amounts to $13.6 \%$, which is nearly 2 times as much as the sector index $6.3 \%$.

The main electric energy consumer is industry whose share in total electric energy consumption when in use in the region is more than half - 57\% (for Moscow it is 55\%, for the oblast it is $67 \%$ ), for public living needs it is $13 \%$, small motoric consumption is $12 \%$, metro is $3 \%$, railroad transport is $6 \%$. Electric energy consumption regime is characterized by large irregularity with great off-peak loads in night hours and short-term (2-3 hours) maximums in the morning and evening hours. Depending on the season of the year and the day of the week the ratio between minimum and maximum loads is in the range of $53-57 \%$,

* Corresponding author: luchkinavv@ mail.ru 
on Monday it is $45-50 \%$. The density of the daily-load curve is $0.81-0.83$. The service hours during load maximum amount to 5470 [1].

The power stations of Moscow power system operate in compliance with the resulting curve specified by the Central Dispatch Office. Besides, regulation is fulfilled of capacity and energy flows via $500 \mathrm{kV}$ network between Mosenergo and the United Power System of the Center. Energy flows have a mutual character. Moscow power system transmits electric power in surplus night hours and receives in deficit diurnal hours. Deficit of peak power and surplus of base power conditions ineffective forced transmission increasing energy losses and complicating conditions of maintaining the specified levels of voltage. The mix of Mosenergo existing generating plants is not optimal and requires increase of power maneuverable power plants. Operation of Moscow energy system for future is planned in conditions of self-balancing. With consideration of introducing new business relationship, meeting an increase of load of most power systems is oriented to development of own power sources and it is doubtful that power will be received by Moscow energy system from outside.

To assess future trends in use of small hydropower potential at preparation of the data for this paper the indices of earlier completed stations have been analyzed. The structure of costs for construction at the existing projects on low-land rivers with small HPPs proves that from 40 to $70 \%$ of total capital investments refer to the costs of creation of water retaining structures and the reservoir. Summarizing this information as well as foreign experience in designing and construction of small HPPs proves that the most promising trend in development of small hydropower potential is search for the sites with the existing water retaining structures. Such sites in Moscow and Moscow Oblast are local drops at water supply and disposal systems of large enterprises, steam power plants, thermal power stations, reservoirs and other structures. Use of the already created head and idle discharges will permit generation of electric power at less cost and without environmental losses.

Construction of small HPPs of such types should be realized within the frame of energy efficiency policy. Apart from incorporation of energy efficiency technologies they may contribute in power supply of enterprises on which they are constructed.

This paper deals with three main trends in using potential of small hydropower of Moscow and Moscow Oblast:

- construction of small NPPs within the industrial structures using a great quantity of water in their process cycles.

- addition of small HPPs to the non-energy reservoirs.

- construction of small NPPs on the unregulated rives of Moscow Oblast.

\section{Materials and Methods}

We have reviewed a large number of industrial enterprises in Moscow and the Moscow Oblast in order to determine and select those of them which flow process is associated with use of large amounts of water.

Accepted enterprises were classified into three groups.

I - power enterprises included co-generation plants and steam power plants.

II - municipal utilities enterprises (water supply stations and water supply-sewage facilities).

III - industrial enterprises using a large amount of water in the flow process.

At the enterprises of Group I (co-generation plants and steam power plants) installation of the Small HPP units is possible at the section of discharge system of water passed through the turbine condensers at a sufficient level difference.

As results from analysis of operation of these objects, the average annual water discharges amount from $201 / \mathrm{s}$ to $25 \mathrm{~m}^{3} / \mathrm{s}$, and the level differences at discharge routes - from tens of centimeters to 10.5 meters. 
In Group II (municipal utilities enterprises) 26 objects were considered. These are water supply stations of Moscow, aeration stations and water supply and sewage facilities of the regional centers of the Moscow Oblast. Construction of small hydropower plants is not efficient at all water supply stations of Moscow due to lack of the level differences at spillage required for the equipment being developed. At aeration stations and municipal sewage disposal facilities, construction of Small HPPs is possible at the spillage after water purification plants if there are sufficient discharges and water level differences.

Based on these provisions, the Small HPPs may be recommended for further consideration at sewage disposal in the town of Podolsk (alternatively, with the length of the supply system $\mathrm{L}=120 \mathrm{~m}-\mathrm{N}=170 \mathrm{~kW}, \mathrm{E}=1$ million $\mathrm{kWh}$ and at $\mathrm{L}=30 \mathrm{~m}-\mathrm{N}=85 \mathrm{~kW}, \mathrm{E}$ $=0.5$ million $\mathrm{kWh}$ ) and Zagorsk (respectively, with $\mathrm{L}=60 \mathrm{~m}-\mathrm{N}=90 \mathrm{~kW}, \mathrm{E}=540$ thousand $\mathrm{kWh}$ and with $\mathrm{L}=25 \mathrm{~m}-\mathrm{N}=70 \mathrm{~kW}, \mathrm{E}=450$ thousand $\mathrm{kWh}$ ).

At the Kuryanovo aeration station, it is possible to obtain $420 \mathrm{~kW}$ and power generation of 2.3 million kWh at the SHPP, but currently at the station, the additional filters are installed for after-treatment of discharged water, which will fully utilize the existing head.

At the remaining facilities of Group II enterprises, the possibility of obtaining electric power at the Small HPP is limited to capacities from 10 to $30 \mathrm{~kW}$ and the output of $60-200$ thousand $\mathrm{kWh}$. According to the accepted classification, Group III includes industrial enterprises of Moscow and Moscow Oblast, in the technological process of which large amounts of water are used. In addition, some large industrial enterprises in the cities of Moscow Oblast receive wastewater from city sewers at their sewage treatment plants.

\subsection{Small HPP at existing non-energy reservoirs}

In the Moscow region, 76 reservoirs with a capacity of over 1 million $\mathrm{m}^{3}$ each are currently in operation. 64 of them do not have HPPs. Most of the reservoirs that are not used for energy purpose were made for the needs of fisheries, irrigation, water supply and industry, water transport. The head created by the dams of waterworks facilities of such reservoirs and water pass to the down stream can be used for energy generation.

Construction of Small HPPs to reservoirs of non energy purpose can improve significantly Small HPPs' engineering-and-economical performance by cutting or avoiding costs for creation of waterfront, reservoir, spillway structures, downstream rearrangement, development of the construction site (roads, power supply to the construction, water supply) and other costs that are unavoidable at the hydropower projects construction.

These costs are commensurable, and often significantly exceed the cost of the energy path of Small HPP. The use of the energy potential of idle discharges from reservoirs of hydroeconomic purpose will also ensure a more complex use of water resources.

In order to select reservoirs, perspective for construction to them Small HPPs, the lower limit of the energy potential of the dam site, equal to 0,5 million kilowatt-hour, what at using of about 5000 hours corresponds to HPP installed capacity of $100 \mathrm{~kW}$ (HPP with power capacity of $100 \mathrm{~kW}$ and lower refer to "micro" category).

Evaluation of the technical hydropower potential of the waterfront is made according to the formula:

$$
\mathrm{E}=\alpha \cdot \mathrm{H}_{\mathrm{s}} \cdot \mathrm{W}_{\mathrm{ds}}
$$

where $\alpha$-scale coefficient

$$
\alpha=9,81 \cdot \eta_{\mathrm{d}} / 3600
$$

unit efficiency $-\eta_{\mathrm{d}}=0,8$

$$
\mathrm{H}_{\mathrm{s}}=\mathrm{H}_{\max }-(\text { FSL-Dead Storage Elevation }) / 3
$$


Where: $\mathrm{H}_{\mathrm{s}}-$ weight-average head, $\mathrm{m}$;

$\mathrm{H}_{\max }$ - maximum head at the dam, $\mathrm{m}$;

$\mathrm{W}_{\mathrm{ds}}$ - volume of water discharge into the downstream in low water with probability $50 \%$, million $\mathrm{m}^{3}$.

Hydroelectic potential of idle discharge of the considered reservoirs is about 60 million kilowatt-hour. 9 projects provide annual output in the amount of 0.5 million kilowatt-hour. They can be recommended for energy use. Their energy efficiency is about 50 million kilowatt-hour - more than $80 \%$ of energy potential of the considered reservoirs. It should be noted that the reservoirs excluded from those promising for energy use are for the most part ponds of fish farms (45 facilities), which, according to fish farming technology, are completely emptied for the winter period (from November to spring flood) and have low hoods (about $2 \mathrm{~m}$ ) [2].

Taking into account single-type layouts and operation mode of the projects, they can be divided into two groups:

The first group.

Waterworks facilities on the Moscow river (Andreevskiy, Trudkommunovskiy, Sofieno, Faustovo, Severniy), Beloomutskiy on the Ob river - are low head navigable. Heads that can be used at HPP, make up 2.5-3.5 m, discharges $-50-60 \mathrm{~m}^{3} / \mathrm{s}$.

The main structures of theses waterworks facilities are movable dam with Poiree systems, earth fill dike, shipping lock. On some of them (Trudkommunovskiy, Andreevskiy) after the dam reconstruction Poiree systems were replaced with spillways with wide sill with flat metal valves. The construction of Small HPP at navigable sections can be performed either after the reconstruction or, which is more correct, simultaneously with reconstruction works.

For such waterworks facilities, a bank layout of a small HPP with head race and tailrace channels is advisable. If a Small HPP is being erected at the same time with the reconstruction works, it is possible to arrange it in the project's waterfront.

The second group.

Ikshinskiy waterworks facility on the Iksha river and Pestovskiy waterworks facility on the Vyaz river are designed for water supply of Moscow. In the downstream of these waterworks, constant releases are made, amounting to about $1 \mathrm{~m}^{3} / \mathrm{s}$. The heads possible for use at HPPs are 13-14 m.

Embankment dam, spillway dam, pipe outlet for compensation flows comprise the main structures of waterworks facilities. For such waterworks facilities layout of HPP with power house at the downstream toe of the dam with water supply to the powerhouse by metal pipes is advisable. In accordance with GOST 19179-73 (Hydrology of land. Terms and definitions) small rivers are the ones with catchment area up to 5 thou. $\mathrm{km}^{2}$, middle - up to 100 thou. $\mathrm{km}^{2}$. In accordance with this classification, the vast majority of rivers flowing within the boundaries of Moscow Oblast are small [3,4].

\subsection{Construction of Small HPPs on small rivers of Moscow Oblast}

In order to assess the feasible scale of the construction of Small HPPs on unregulated small waterflows of Moscow Oblast, it is necessary to draw up an energy use plan for each of them. However, such a design study has no practical significance.

The cost of building a small hydropower station in the damsites with a ready waterfront is already at a level close to the maximum allowable due to the high cost of the process equipment and relatively low energy efficiency. As a result, in the present work, from all the variety of small rivers, the groups are identified with common defining features, in each group characteristic waterflows are marked, on which the schemes of energy use are made. Small HPP engineering-and-economical performance is based on this data [5]. 
Due to the fact, that the natural conditions of Moscow Oblast river basins (hydrological, geological, climatic) and development of river valleys are similar, the potential water flow capacity is taken as the defining feature of the river breakdown in the groups. The rivers of Moscow oblast are divided in power into 4 groups:

1. Rivers with potential capacity up to $2 \mathrm{MW}$

2. Rivers with potential capacity from 2.1 to $10 \mathrm{MW}$

3. Rivers with potential capacity from 10.1 to $50 \mathrm{MW}$

4. Rivers with a potential capacity from 50.1 to $100 \mathrm{MW}$.

These are lowland rivers with a developed bilateral, in some places marshy flood plain. In the geological structure of the river valleys, the Permian, Triassic, Jurassic, Carboniferous and Quaternary rocks are involved. The width of the rivers ranges from 5-20-80 $\mathrm{m}$ in the upper reaches to $20-200-400 \mathrm{~m}$ in the mouth. Depths range from 0.2-0.6 $\mathrm{m}$ in the shallows, to $0.8-2.0 \mathrm{~m}$ in the reaches. The main feed of the rivers is precipitation. The rivers of this type are characterized by high spring floods (65-70\% of the annual flow), low summerautumn low water periods (15-20\% of the annual flow) with separate rain floods in the summer and autumn lasting up to 30 days. A steady winter cover is formed in November and begins to thaw in April. Minimum winter horizons are set at the end of December. Ice age lasts from 130 to 135 days. The average ice thickness is $35-65 \mathrm{~cm}$.

The most numerous are rivers with a potential capacity of up to $10 \mathrm{MW}$ [6].

Typical of these groups of watercourses are the Polya River (right tributary of the Klyazma River) with a potential capacity of 1.4 MW and the Verya River (the left tributary of the Klyazma River) with a potential capacity of $3.2 \mathrm{MW}$.

Based on the analysis of natural and economic conditions and given that the rivers in question flow in densely populated areas, the fundamental possibility of the energy use of these watercourses was considered in two alternatives:

- construction of low-head SHPPs without reaching the elevations of the normal HWLs to the floodplain;

- construction of SHPPs with seasonal storage reservoirs with flooding of floodplain lands.

The third and fourth groups include only 3 rivers: Klyazma, Oka, Moscow. These rivers basically have already regulated flow, their valleys are almost completely developed.

\section{Results}

The problems of development of energy sources, along with the shortage of fossil fuels, are complicated by the environmental stress of such a large industrial region like the Moscow Region. In the emerging difficult operating conditions, great importance is attached to energy saving measures. The options of covering up to $50 \%$ of the increments of power consumption of the power system due to energy saving are considered. Development of the potential of small hydropower in the region may have a certain value in the system of these measures.

The assessment of the feasible scale of development of the potential of small hydropower in Moscow and the Moscow region in this work was carried out in four areas:

- construction of a small hydropower plant as part of industrial facilities that use a greater amount of water in technological cycles,

- construction of small hydroelectric power station to non-energy reservoirs,

- construction of small hydropower plants on unregulated watercourses.

In the Moscow region, more than 2.5 thousand industrial enterprises that use large amounts of water in technological processes have been identified. According to preliminary estimates, only 50 facilities with water intake or discharge in an amount of more than 10 million $\mathrm{m} 3$ per year may be of interest to the power industry. The hydropower potential of the idle discharges 
of these projects makes up about 22 million $\mathrm{kWh}$. Among these projects there are 3 groups of enterprises:

- 11 energy enterprises (Co-generation plants and Steam power plants), where the installation of small HPP units is possible at level differences of the cooling discharge systems; the cost of construction of the small hydropower station is 2000-5000 rubles / $\mathrm{kW}$; the greatest energy effect can be obtained at two projects: the discharge of the Kashirskaya Steam Power plant-4 $(\mathrm{N}$ inst. $=2.25 \mathrm{MW}, \mathrm{E}=12.7$ million $\mathrm{kWh})$ and the discharge of Cogeneration plant $-9(\mathrm{~N}$ set. $=140 \mathrm{~kW}, \mathrm{E}=0.85$ million $\mathrm{kWh})$, at the remaining facilities, the possibility of obtaining energy is limited to capacities of $20-50 \mathrm{~kW}$ and energy generation $0.2-0.4$ million $\mathrm{kWh}$.

- 26 public utilities (water stations, aeration stations, water supply and sewerage enterprises), where the construction of the small HPP is possible at level differences of the sewage discharges, sewage treatment plants, etc., the possibility of obtaining energy is limited to capacities from $10-30$ to $170 \mathrm{~kW}$ and energy production $0.66-0.2$ to 1 million $\mathrm{kWh}$ with costs of 2000-3000 rubles/kW.

- 13 industrial enterprises using large quantities of water in technological processes (chemical, foundries, etc.); the use of level difference head drops allows obtaining power from 30 to $100 \mathrm{~kW}$ and energy generation from 0.2 to 0.6 million $\mathrm{kWh}$ with costs of 1700 $4000 \mathrm{rub} / \mathrm{kW}$ [7].

In the Moscow Region there are 64 reservoirs with a capacity of over 1 million $\mathrm{m} 3$ each, which do not have a hydroelectric power station. The hydropower potential of idle discharges from these reservoirs is about 60 million $\mathrm{kWh} .80 \%$ of the energy potential (about 50 million $\mathrm{kWh}$ ) is concentrated on 9 projects that can be recommended for energy use. According to the technical solutions and modes of operation, these projects are classified into two groups:

- water transport waterworks on the Moscow and Oka River (7 projects); the use of the shipping releases of these projects makes it possible to obtain capacities from 1 to $3.8 \mathrm{MW}$ of power generation from 6 to 15 million $\mathrm{kWh}$ per year at costs ranging from 3,000 to 7,000 rubles / $\mathrm{kW}$.

- waterworks for water supply (2 projects); the use of constant releases in the downstream during the year will provide power of about $100 \mathrm{~kW}$ and energy production of about 1 million $\mathrm{kWh}$ at a cost of about 2000 rubles / $\mathrm{kW}$.

To assess the feasible scale of the construction of small hydroelectric power plants on unregulated small water courses of the region as per selected typical water courses the energy utilization scheme were drawn up in two alternatives:

- construction of low-head SHPPs without reaching NWL elevations to the floodplain;

- construction of SHPPs with seasonal reservoir regulation and flooding of floodplain lands.

\section{Conclusions}

Out of 109 rivers accounted for in the region, 105 rivers belong to the categories of small, of which $40 \%$ have a hydropower potential of up to $2 \mathrm{MW}$ and $60 \%$ of a rivers have a hydropower potential of 2-10 MW. The typical of these groups of water courses have been chosen the Polya River (right tributary of the Klyazma river) with a potential capacity of 1.4 MW and the Verya River (the left tributary of the Klyazma River) with potential capacity of 3.2 MW. Completed studies have shown that without the NHL elevations on the floodplain, on the rivers of the first group, it is possible to construct micro hydropower plants, on the rivers of the second group it is possible to obtain heads up to $5 \mathrm{~m}$, the capacity - up to 130 $150 \mathrm{~kW}$ with energy generation of about 1 million $\mathrm{kWh}$. 
When regulating the runoff, it is possible to obtain capacities from 300 to $1.000 \mathrm{~kW}$ with energy output from 2 to 6 million kWh. However, the construction of small HPPs with seasonal reservoirs on the rivers under consideration due to intensive agricultural development of their floodplains is very problematic.

\section{References}

1. V.V. Luchkina, IOP Conf. Series: Earth and Environmental Science 90, 1-6 (2017)

2. R.R. Kazaryan, MATEC Web of Conferences 193, 01009 (2018)

3. S.A. Sinenko, MATEC Web of Conferences 21, 09007 (2017)

4. S.A. Sinenko, MATEC Web of Conferences 21, 09009 (2017)

5. A. Mottaeva, MATEC Web of Conferences 193, 01022 (2018)

6. E. Vasilyeva, MATEC Web of Conferences 170, 01050 (2018)

7. B.V. Zhadanovsky, S.A. Sinenko, Computing in Civil and Building Engineering Proceedings International Conference 1, 137-142 (2014) 